\title{
MEDICINE AND THE LAW Termination of pregnancy and children: Consent and confidentiality issues
}

\author{
David McQuoid-Mason
}

While the Choice on Termination of Pregnancy Act ${ }^{1}$ (Choice Act) allows a female of any age to consent to a termination of pregnancy, ${ }^{2}$ there are other statutes, such as the Child Care $\mathrm{Act}^{3}$ and the Children's Act, ${ }^{4}$ that provide for different ages of consent for medical and surgical procedures. Doctors are not always certain whether young girls are legally capable of giving proper informed consent for certain associated procedures when undergoing a termination of pregnancy. Furthermore, the Criminal Law (Sexual Offences and Related Matters) Amendment Act ${ }^{5}$ (the Sexual Offences Act), which imposes a duty to report sexual offences against children, seems to undermine the girl-child patient's right to confidentiality.

\section{Consent to termination of pregnancy by minors}

There is a need to clarify the position concerning consent by minors to certain procedures in respect of terminations of pregnancy. The provisions in the Choice Act ${ }^{1}$ allowing consent to a termination of pregnancy by girls of any age are not affected by the Child Care Act ${ }^{3}$ or the Children's Act. ${ }^{4}$ In respect of other procedures, the provisions of the Child Care Act regarding consent to medical treatment by children over the age of 14 years and surgical operations by persons over the age of 18 years were due to continue to stand until the relevant provisions of the Children's Act came into effect on 1 April 2010.

The Children's Act introduces drastic changes to the capacity of children to consent to medical treatment and surgical operations. Children who are of 12 years of age or over, and who are of sufficient maturity and have the mental capacity to understand the benefits, risks, social and other implications of medical treatment, may consent to such treatment without assistance from their parents or guardians. Children of 12 years of age or over, and of sufficient maturity, will be able to consent to surgical operations if they are assisted by their parents or guardians. ${ }^{6}$

Although the Choice Act states that a female of any age may consent to a termination of pregnancy, ${ }^{2}$ such a patient must be capable of giving informed consent. The provisions of the Children's Act in respect of sufficient maturity provide useful guidelines in this regard. If the child is not capable of giving

David McQuoid-Mason is Professor of Law at the Centre for Socio-Legal Studies, University of KwaZulu-Natal, Durban, and publishes and teaches in medical law.

Corresponding author: D J McQuoid-Mason (mcquoidm@ukzn.ac.za) such consent to a termination of pregnancy she must be told that her parent's or guardian's consent is required, except in an emergency and/or if a parent or guardian cannot be contacted, when the procedure can be done without consent ${ }^{7}$ or with the consent of the medical superintendent of a hospital. ${ }^{8}$

The present provisions of the Child Care Act ${ }^{3}$ do not apply to the Choice $\mathrm{Act}^{1}$ because if only girls over the age of 14 years were capable of consenting to medical treatment associated with a termination of pregnancy the purpose of the Choice Act would be undermined. Similarly, when the relevant section of the Children's Act ${ }^{6}$ dealing with consent to medical treatment by children of 12 years or older comes into effect, the provision will not affect terminations of pregnancy under the Choice Act.

The Children's Act has lowered the age of majority to 18 years, ${ }^{9}$ but girl patients under18 years of age may still consent to surgical operations associated with a termination of pregnancy. This is because it would undermine the purpose of the Choice Act if only women over the age of 18 years were capable of consenting to such operations. When the relevant section of the Children's Act ${ }^{6}$ comes into effect, sufficiently mature children of 12 years or older may consent to surgical operations with the assistance of their parents or guardians, but this will not apply to terminations of pregnancy in terms of the Choice Act.

\section{Confidentiality and termination of pregnancy by minors}

Questions of privacy and confidentiality must also be clarified in the context of terminations of pregnancy by minors. Confidentiality is an integral part of medical practice and the right to privacy which is protected by the Constitution, ${ }^{10}$ the National Health Act ${ }^{11}$ and the common law. A breach of confidentiality and the right to privacy may result in legal action unless there is a valid defence such as consent, a court order, a statutory duty, necessity, or a privileged occasion. ${ }^{12}$

The Sexual Offences Act ${ }^{5}$ provides that a person who has knowledge that a sexual offence has been committed against a child must report such knowledge to a police official immediately. The Act creates the offence of consensual sexual penetration with a person under the age of 16 years or statutory rape. ${ }^{13}$ However, whether a doctor who terminates a pregnancy of a girl under the age of 16 years must report the matter as a sexual offence against the child, depends upon the age of the male who has had sexual intercourse with the girl.

The Sexual Offences Act provides that if there is less than 2 years' age difference between a boy and a girl who have had consensual sex, and they are both under 18 years of age, it will be a good defence to a charge of statutory rape. ${ }^{14}$ It could therefore be argued that it is not necessary for the medical practitioner to report such a girl-child's condition to the 


\section{FORUM}

authorities as arising from statutory rape. Where a girl under 16 years of age is pregnant as a result of having had sexual intercourse with a male who is more than 2 years older than her, however, the doctor has a duty to report it to the police. ${ }^{5}$ The provisions not yet in force in the Children's Amendment Act ${ }^{15}$ also impose a duty on medical practitioners and others to report sexual abuse of children.

Where there is a duty on doctors and others to report sexual offences against children they may only refrain from doing so where they have a valid defence such as necessity. The defence of necessity applies where a person acts to protect their own or somebody else's legally recognised interest (e.g. their life or bodily integrity), which is threatened with immediate harm. ${ }^{16}$ Although it is a crime not to report sexual offences against children, ${ }^{5}$ a doctor who is prosecuted in terms of the Sexual Offences Act for failing to report statutory rape may therefore be able to rely on the defence of necessity in situations where, for example, the girl patient threatens to expose herself to harm and illegal conduct by going to a back-street abortionist, and the doctor reasonably believes that she will do so.

Medical emergencies also give rise to confidentiality problems in respect of terminations of pregnancy involving children. In such circumstances, the doctor should ask the patient whether she would like her parent or guardian to be informed if a medical emergency should arise, or whether she would like to make a written nomination of a proxy to make decisions for her in terms of the National Health Act. ${ }^{17}$
Where emergency situations have not been discussed, doctors may claim a qualified privilege ${ }^{12}$ should they decide that it is necessary to inform the girl's parent or guardian about an emergency and the patient has not prohibited this. In these circumstances it could be argued that the practitioner has a good defence, because he or she had a moral, legal or social duty to act in the best interests of the child and to inform the girl's parent or guardian, and the latter had a reciprocal interest in receiving the information. ${ }^{18}$

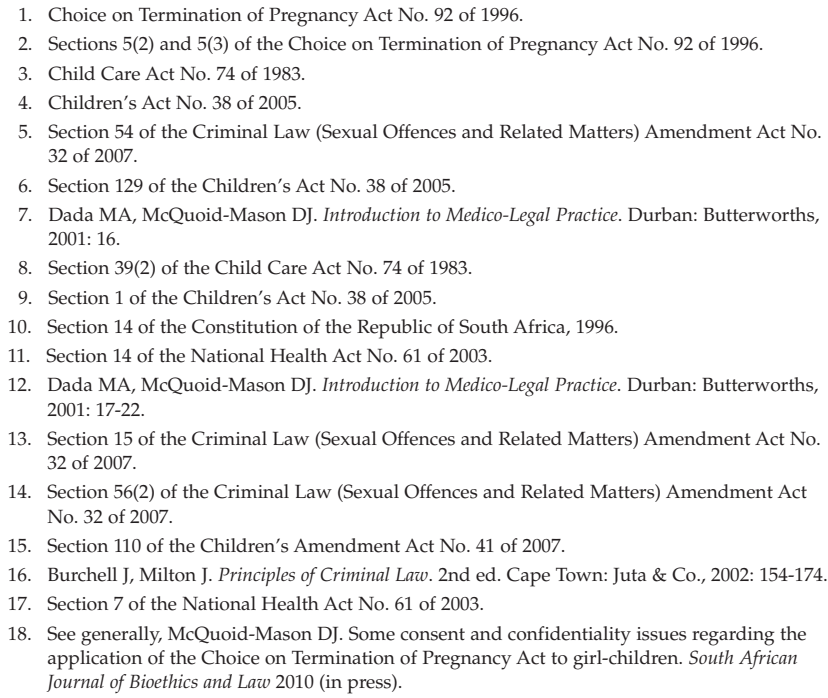

